\section{Towards a New World synthesis}

\author{
Colin A. Russell
}

Chemistry in America, 1876-1976. By Arnold Thackray, Jeffrey L. Sturchio, P. Thomas Carroll and Robert Bud. Reidel: 1985. Pp.564. Dfl.210, \$79.50, £3.50.

A CASUAL reader who decides to browse through this volume is in for quite a surprise. From the title one might expect an account of American chemistry (here meaning chemistry in the United States) on the lines of those engaging and oncepopular series "a hundred years of this or that": bland, popular, anecdotal, synoptic, well-illustrated, easy on the eye and reasonably analytical. For the price and size one might expect all this on a lavish scale. Should our browser dally even for a moment at the title page he will, however, receive the first hint of unpredictability. The subtitle "historical indicators" suggests uncharted seas ahead. For, if these are not to do with the litmus-type indicators familiar to all chemists, what on earth are they? The confusion is not resolved by the apparently perverse and deliberate appropriation of the very phrase "chemical indicators" that has for so long had a quite precise if pedestrian connotation of an entirely different kind.

"Indicators", as used by these authors, are long-running trends in a series of statistical data. They are measurements of change. If, for example, you analyse census and other information about the employment of chemists in the United States, you find for the past century or so an annual growth rate of about five per cent in the chemical work-force, and that chemists have increased from 2 to 15 per 10,000 of the total numbers employed in any work. On the other hand, the proportion of high school chemical students who later specialize in chemistry has declined steadily, as has the esteem accorded to chemistry in public opinion surveys and its coverage in newspapers. And since about 1910 there has been absolute growth but relative decline in the place of chemistry in the internal economy of American universities.

In six chapters, occupying less than half the book, the authors present a profusion of tables, graphs, bar-charts and the like to show how American chemistry has changed in the context of industry, education and its professional organization. Their conclusions are helpfully summarized in each chapter by a few "indicator highlights". For people who are prepared to take the arguments on trust these brief conclusions are probably all that matter: two or three pages of print altogether. However with typical trans-Atlantic thoroughness the authors will not allow and useful information, especially if they are concerned with institutions or education. Yet the book also has drawbacks for such people. The material relates to only one country - though admittedly a world leader in chemical research - and one is bound to seek comparisons with Britain, Germany and other countries if only for the earlier part of the period under consideration. Moreover, it is important that not only should national trends be compared but that allowance be made for different meanings for the variables measured. Thus the criterion of professionalization in chemistry is a very American one and different from that in Britain where the phenomenon first arose. Similar caution must be given about the definition of various classes of chemists which mean different things in different countries; "assayer" is a case in point.

It is not difficult to criticize the selection and presentation of the data. One looks in vain for information on such topical issues as the changing role and numbers of women in chemistry, the relation between chemistry and war, and even the question of chemists' salaries. In education, trends in chemistry are compared with those in history rather than in physics and biology. Again, there are surely more important issues to record than the number of exchemists who become deans in American universities or the ages (high) of Presidents of the American Chemical Society. However, the prominence given to that specific institution is one of the particularly creditable features of a book that is always in danger of submersion in an ocean of generalities.

In reading the book $\mathrm{I}$ became gradually conscious of a sense of déjà vu. Somewhere I had met something very like it before, but where? The impression crystallized into recognition by about Chapter 3. Its predecessor was nothing less than the massive History of Chemistry by J.R. Partington, published by Macmillan in four volumes between 1961 and 1970 . Superficially the two works are light-years apart yet fundamentally they are doing the same thing: presenting a highly idiosyncratic view of a mountain of information with little or no attempt to digest it into a coherent, readable overview of the subject. Here, perhaps, is a Partington of a new era, with all the weaknesses and strengths of the original. Indigestible it may be, and one could certainly not read it from cover to cover. But if it turns out to be half as useful as Partington in supplying raw information and in catalysing future work, it will earn the gratitude of generations to come. Whether the trends it heralds in chemical history - empirical, pragmatic and semi-quantitative - will prove to be fruitful, time alone will tell.

Colin A. Russell is Professor of History of Science and Technology and Director of the History of Chemistry Research Group, Open University, Walton Hall, Milton Keynes MK7 $6 A A, U K$. 